\title{
A INFLUÊNCIA DA FRAÇÃO VOLUMÉTRICA DE ARGÔNIO SOBRE O PADRÃO DE FLUXO NO MOLDE NO LINGOTAMENTO CONTÍNUO DE PLACAS*
}

\author{
Alexandre Dolabella Resende ${ }^{1}$ \\ Letícia Mangualde Araújo ${ }^{2}$ \\ Ramon Fraga Resende ${ }^{3}$ \\ Rubens Alves Freire ${ }^{4}$
}

\section{Resumo}

O estudo do padrão de fluxo do aço no molde de lingotamento contínuo é de grande importância para a siderurgia, uma vez que permite compreender como as variáveis de processo afetam a qualidade do aço produzido. Existem diversas técnicas, numéricas ou experimentais, utilizadas para realizar esses estudos. Este trabalho apresenta um estudo de simulação numérica, que tem como objetivo avaliar a influência da fração de argônio injetada no sistema no padrão de fluxo do aço no molde de lingotamento de placas. As condições de processo simuladas foram obtidas de diversas máquinas de lingotamento, com diferentes vazões de aço e argônio injetado. Os resultados numéricos foram validados através de um método experimental denominado "Nail Board". Após a realização do estudo, foram constatadas consideráveis alterações do padrão de fluxo devido à variação da fração volumétrica do argônio injetado no sistema.

Palavras-chave: Lingotamento; “Nail Board”; Simulação numérica; Padrão de fluxo.

\section{"THE INFLUENCE OF THE ARGON VOLUME FRACTION ON THE FLUID FLOW PATTERN IN THE SLAB CONTINUOUS CASTING MOLD"}

\begin{abstract}
The study of the fluid flow pattern in the continuous casting mold is of great importance for the steel industry, since it provides an insight into how the process variables can affect the quality of the steel produced. Many techniques, whether numerical or experimental, are used in these types of studies. This article presents a numerical simulation study which aims to evaluate the influence of the argon fraction injected in the system on the fluid flow pattern of the slab continuous casting mold. The process conditions simulated were obtained from various continuous casting machines, with different steel throughputs and argon flow rates. The results were validated through an experimental method called Nail Board. Significant changes were observed in the flow pattern due to variations in the argon fraction injected into the system.
\end{abstract}

Keywords: Continuous casting; Nail board; Numerical simulation; Fluid flow pattern.

1 Engenheiro Mecânico, Engenheiro de Desenvolvimento, Engenharia de Soluções, Magnesita Refratários S.A., Contagem. Minas Gerais, Brasil.

2 Engenheira Metalurgista, Engenheira de Qualidade, Gerência de Controle de Qualidade, Magnesita Refratários S.A., Contagem. Minas Gerais, Brasil.

3 Engenheiro Mecânico, Engenheiro de Assistência Técnica, Gerência de Assistência Técnica, Magnesita Refratários S.A., Contagem. Minas Gerais, Brasil.

4 Engenheiro Mecânico, Coordenador de Projetos Mecânicos e Simulações Numéricas, Engenharia de Soluções, Magnesita Refratários S.A., Contagem. Minas Gerais, Brasil. 


\section{INTRODUÇÃO}

O estudo do padrão de fluxo do aço no molde de lingotamento contínuo é de grande importância para a siderurgia, uma vez que muitos problemas de qualidade do aço são originados nessa etapa do processo e estão diretamente atribuídos a um baixo controle das condições do fluxo no molde.

Problemas de qualidade de grande relevância são o aprisionamento de bolhas de argônio e partículas não metálicas no aço. De acordo com Thomas [1], "a presença dessas partículas conduz eventualmente a defeitos de superfície ou a defeitos internos, que agem como concentradores de tensões e reduzem as propriedades mecânicas do produto final".

As bolhas de argônio, além de se apresentarem como potenciais impurezas no produto lingotado, também influenciam significativamente o padrão de fluxo do aço no molde. Estudos realizados por Thomas et al. [2] mostram esse efeito ao retratar a possível reversão do sentido do fluxo na região do menisco à medida que a fração volumétrica de argônio cresce a valores superiores a $10 \%$.

Devido à tamanha relevância dos efeitos que o padrão de fluxo pode causar no produto acabado, são feitos constantes esforços no estudo do processo de lingotamento contínuo para se desenvolver ferramentas que possibilitem um melhor controle do fluxo de aço no molde e que gerem melhores soluções de problemas de interesse prático. Alguns métodos, tanto experimentais como numéricos, foram desenvolvidos com a finalidade de se conhecer melhor o escoamento do aço no molde.

Existem diversos métodos experimentais para se estimar o padrão de fluxo no menisco citados nos trabalhos de Liu et al. [3] e Rice et al. [4] que, apesar de serem eficientes e precisos, requerem análises complexas de hidrodinâmica e eletromagnetismo, além de altos investimentos. Na tentativa de se encontrar um método simples, de baixo custo e ainda que permitisse a determinação do padrão de fluxo, Dauby et al. [5] e Thomas et al. [6] criaram e desenvolveram o método do "Nail Board", ferramenta capaz de fornecer uma estimativa das velocidades pontuais no menisco do molde.

O "Nail Board" consiste de fileiras de pregos de aço paralelos, fixados em uma base longa em pontos eqüidistantes. Esses pregos são imersos no molde pelo menisco, passando pelo pó fluxante, pela camada de escória e alcançando o nível de aço líquido. Após alguns segundos, os pregos são removidos do molde, e então, medese a fina camada de aço solidificado ao redor de cada prego.

Pelo Princípio de Conservação de Energia, sabe-se que quando o aço líquido em movimento se depara com o prego, há elevação do nível da interface aço-escória, ou seja, a energia cinética associada a este escoamento se transforma em energia potencial, o que faz com que o aço perca velocidade e suba no prego até que alcance um determinado ponto de estagnação. Essa diferença de altura da camada de aço gerada ao redor do prego permite a obtenção do sentido de escoamento do aço, ou seja, da sua velocidade, que é da extremidade mais alta para a extremidade mais baixa da camada solidificada, conforme mostram as Figuras 1 e 2. 

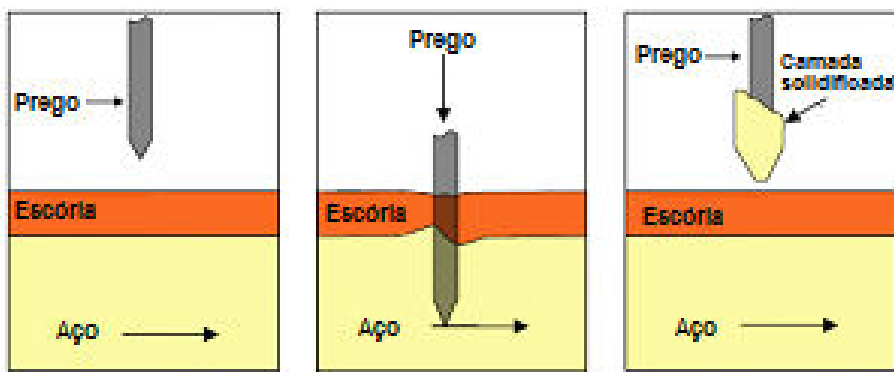

Figura 1. Etapas do teste do "Nail Board". (Liu et al.[3]; adaptada).

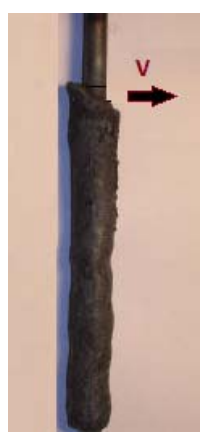

Figura 2. Camada solidificada e diferença de altura indicando sentido da velocidade (Rietow et al.[7]; adaptada).

Após a realização do teste e a análise dos pregos, são obtidos padrões de fluxo no menisco que devem ser registrados conforme ilustra a Figura 3, obtida em Visser [8].
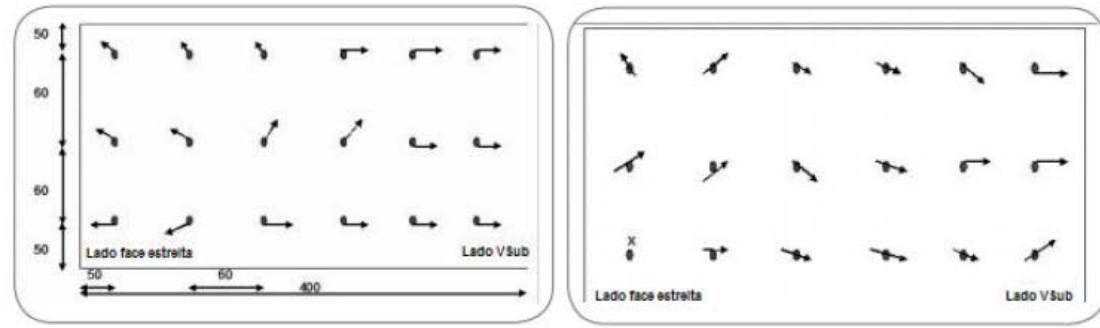

Figura 3. Exemplos de padrões de fluxo no menisco obtidos pelo teste do "Nail Board". (Visser [8]; adaptada).

Dauby et al. [9] utilizaram o "Nail Board" para determinar o padrão de fluxo no molde, podendo ele ser caracterizado como "single roll", "double roll" ou instável, conforme exemplifica a Figura 4. Durante esses testes, variou-se a largura do molde; a velocidade de lingotamento; a taxa de argônio injetada; o projeto e a profundidade de imersão da válvula submersa. Os resultados mostraram que a variação destes parâmetros de operação altera de maneira significativa o perfil de fluxo obtido.

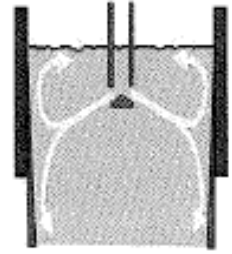

(a)

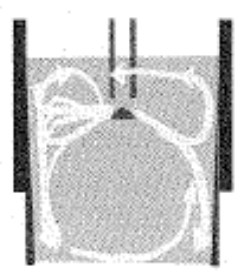

(b)

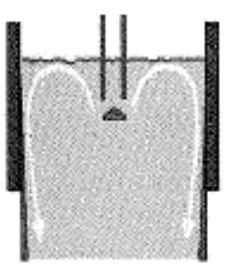

(c)

Figura 4. Tipos de padrão de fluxo observados no molde.

(a): "double roll"; (b): instável; (c): "single roll". [Dauby et al.[9]; adaptada].

Os métodos experimentais possuem a vantagem de fornecerem informações coletadas diretamente no processo, sem a introdução de hipóteses simplificadoras comuns em estudos de modelagem. Por outro lado, são restritos a regiões específicas do molde, nesse caso permitindo o conhecimento somente do padrão de fluxo na região do menisco. Além disso, apresentam a desvantagem de fornecer respostas somente para as condições de processo utilizadas no momento do experimento. Não é possível, através desses métodos, estimar o padrão de fluxo obtido sob diferentes condições antes de efetuar tais alterações na prática, o que pode trazer conseqüências indesejáveis na produtividade e qualidade do produto final. 
Nesse contexto, os métodos numéricos apresentam a vantagem de fornecer informações sobre como determinadas variáveis, como por exemplo, a vazão de argônio, influenciam o comportamento do fluxo no molde. Com base nos estudos numéricos, pode se avaliar o padrão de fluxo sob diferentes condições e então prever qual configuração possui maior probabilidade de gerar melhores resultados no processo. Dessa forma, pode se realizar os testes na planta somente para a configuração escolhida. A principal desvantagem da abordagem numérica é a introdução de simplificações, o que gera a necessidade de seus resultados serem validados pelas medições experimentais como forma de garantir a credibilidade do modelo.

O presente trabalho é um estudo de simulação numérica, que tem como objetivo avaliar como a fração de argônio injetada influencia o padrão de fluxo do aço no molde de lingotamento de placas. As condições de processo simuladas foram obtidas de diversas máquinas de lingotamento, com diferentes vazões de aço e argônio injetado, e os resultados numéricos foram validados através do "Nail Board".

\section{MATERIAIS E MÉTODOS}

\subsection{MÉTODO EXPERIMENTAL: "NAIL BOARD"}

As bases longas foram confeccionadas com materiais simples, como madeira, pregos e porcas para a fixação dos pregos, como ilustrado pela Figura 5.

Dispositivos foram confeccionados e parafusados às bases para facilitar o seu manuseio.

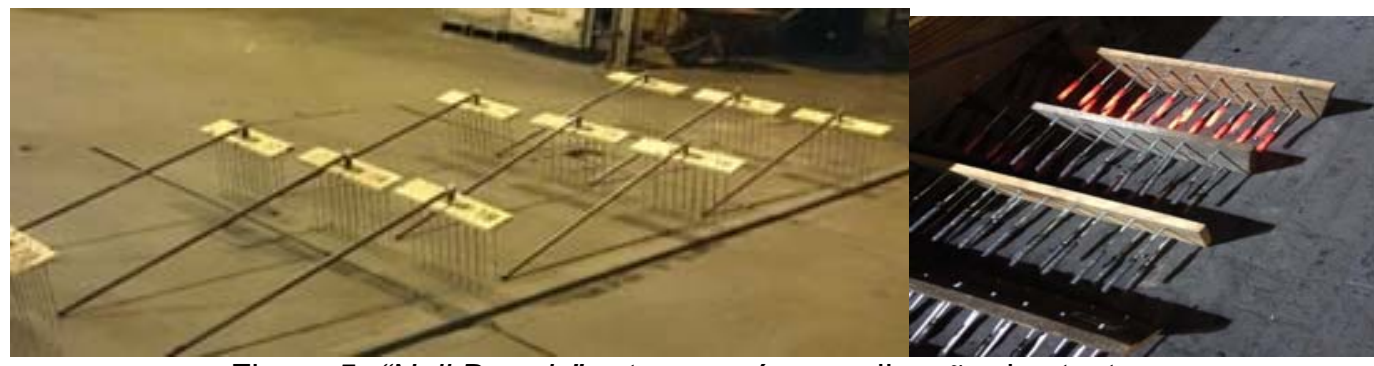

Figura 5. "Nail Boards" antes e após a realização dos testes

A Figura 6 mostra as três etapas de um dos testes realizados para este estudo:

(a) Imersão perpendicular dos pregos no molde;

(b) Pregos imersos por curto período de tempo;

(c) Remoção dos pregos para a análise da camada solidificada obtida.

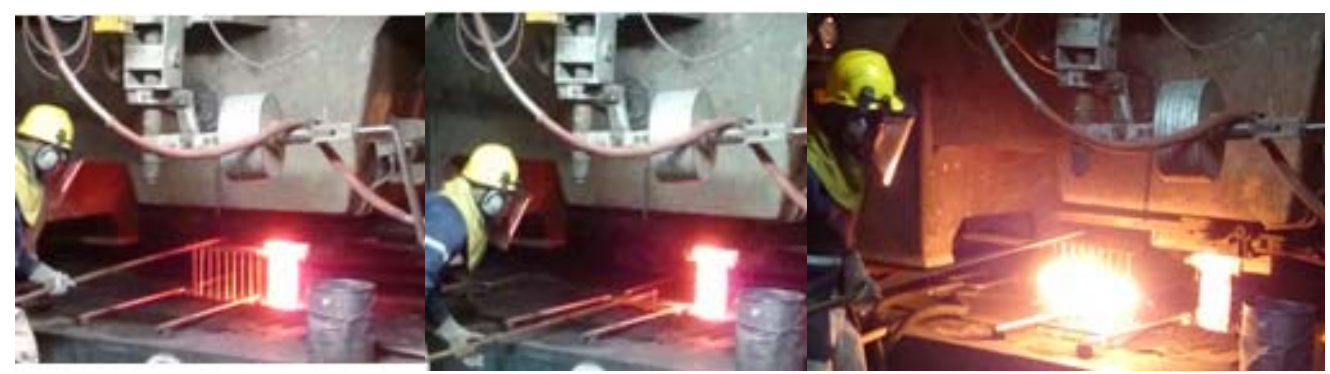

(a)

(b)

(c)

Figura 6. Realização de um teste "Nail Board". 
A Figura 7 abaixo ilustra o esquema de posicionamento do "Nail Board" no molde. A ferramenta deve estar centralizada entre a face estreita do molde e a válvula submersa. A distância entre os pregos foi padronizada em $50 \mathrm{~mm}$. A quantidade de pregos pode variar de acordo com as dimensões dos moldes.

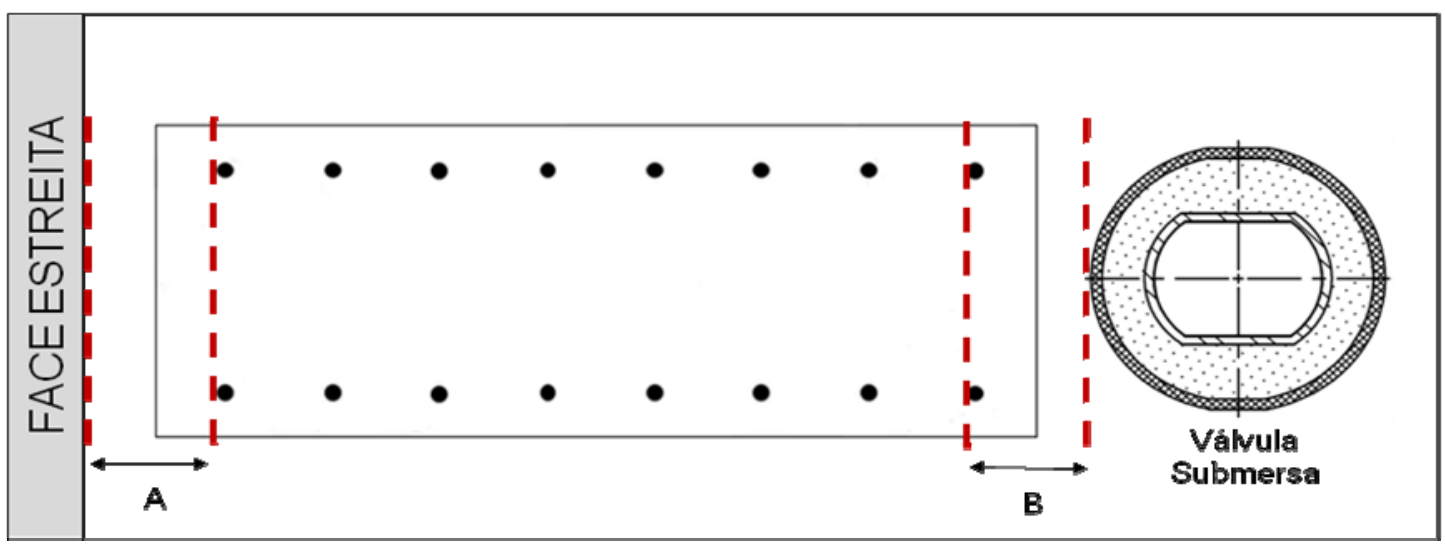

Figura 7. Esquema de posicionamento do "Nail Board" no molde.

Os testes foram realizados em três siderúrgicas de lingotamento de placas e em cada teste foram utilizados 10 "Nail Boards" para cada condição testada. As condições de lingotamento para cada caso foram registradas: dimensões do molde, velocidade de lingotamento, vazão de argônio injetado, dentre outras.

\subsection{MÉTODOS DE SIMULAÇÃO}

Para o estudo de fenômenos relacionados a escoamentos de líquidos e gases, a técnica numérica mais difundida é o método dos volumes finitos. O problema de interesse é modelado em uma plataforma computacional e o domínio é discretizado em células nas quais as equações diferenciais parciais que regem a mecânica dos fluidos são linearizadas e resolvidas de forma simultânea e interligada. As soluções obtidas permitem conhecer valores teóricos de grandezas de interesse, como pressões e velocidades em todo o domínio simulado. Consequentemente, é possível adquirir uma compreensão geral do padrão de fluxo para as condições simuladas.

Nesse trabalho, as simulações foram realizadas através da plataforma ANSYS CFX. As equações de transporte foram resolvidas para os valores médios das velocidades ao longo do tempo, com filtragem das oscilações turbulentas. Essa abordagem é conhecida como RANS (Reynolds Averaged Navier-Stokes) e permite a obtenção de resultados com maior praticidade e menor custo computacional quando comparada a modelagens que buscam calcular diretamente as flutuações turbulentas.

Foram simulados os casos para os quais foram realizados os "Nail Boards", com o objetivo de utilizar os resultados experimentais como validação da solução numérica.

\section{RESULTADOS E DISCUSSÃO}

A Tabela 1 mostra os principais parâmetros de processo para os três casos avaliados: 
Tabela 1. Condições estudadas pela simulação e pelo "Nail Board"

\begin{tabular}{lccccccc}
\hline Caso & $\begin{array}{c}\text { Largura } \\
\text { do } \\
\text { molde } \\
(\mathbf{m m})\end{array}$ & $\begin{array}{c}\text { Espessura } \\
\text { do molde } \\
(\mathbf{m m})\end{array}$ & $\begin{array}{c}\text { Velocidade } \\
\text { de } \\
\text { lingotamento } \\
(\mathbf{m} / \text { min) }\end{array}$ & $\begin{array}{c}\text { Vazão } \\
\text { de aço } \\
\text { (ton/min) }\end{array}$ & $\begin{array}{c}\text { Vazão } \\
\text { de } \\
\text { argônio } \\
\text { (NL/min) }\end{array}$ & $\begin{array}{c}\text { Fração } \\
\text { volumétrica } \\
\text { de argônio }\end{array}$ & $\begin{array}{c}\text { Método } \\
\text { de } \\
\text { controle } \\
\text { de fluxo }\end{array}$ \\
\hline $\mathrm{A}$ & 1600 & 250 & 0,8 & 5,6 & 2,6 & $4 \%$ & Tampão \\
\hline $\mathrm{B}$ & 1300 & 250 & 1,0 & 7,0 & 13 & $20 \%$ & Tampão \\
\hline $\mathrm{C}$ & 1300 & 250 & 1,2 & 8,4 & 13 & $17 \%$ & Gaveta \\
\hline
\end{tabular}

Para o cálculo da fração volumétrica de argônio presente no molde, foi considerado um fator de expansão devido ao aumento de temperatura e variações de pressão igual a 5 vezes o volume do argônio frio. A escolha desse número foi baseada nos cálculos realizados no trabalho de Thomas et al. [2].

As Figuras 8,9 e 10 mostram os resultados obtidos por ambos os métodos para padrão de fluxo na região do menisco. Em todos os casos, a simulação e os "Nail Boards" previram a direção e o sentido macroscópico do fluxo, o que mostra que o modelo está validado para a avaliação do perfil qualitativo do fluxo no molde.

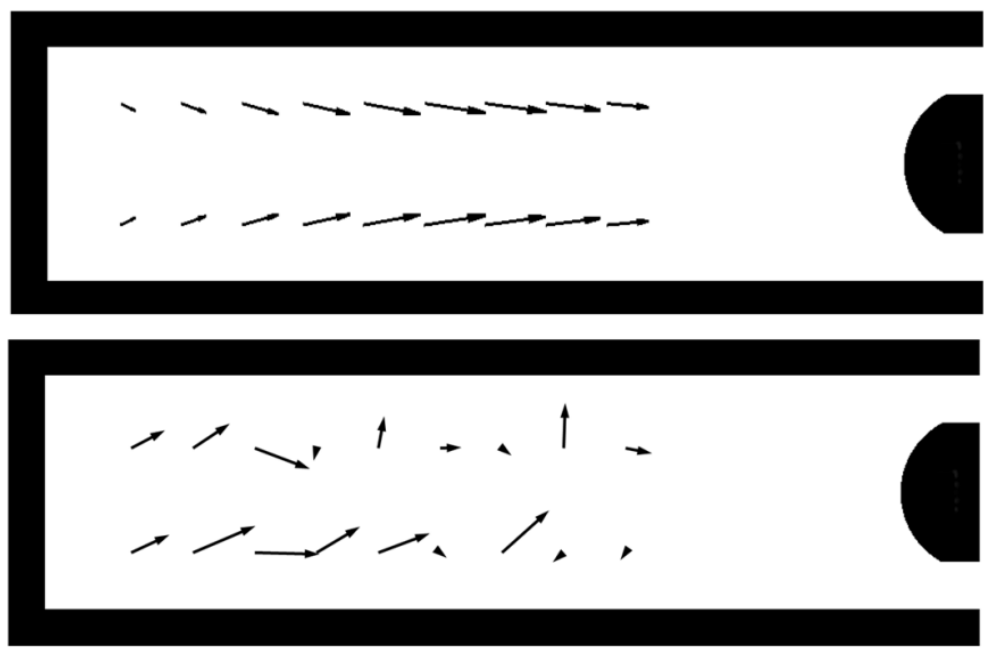

Figura 8. Padrão de fluxo no menisco para o caso A. Simulação (acima) e "Nail board" (abaixo). Fração volumétrica de argônio: $4 \%$.

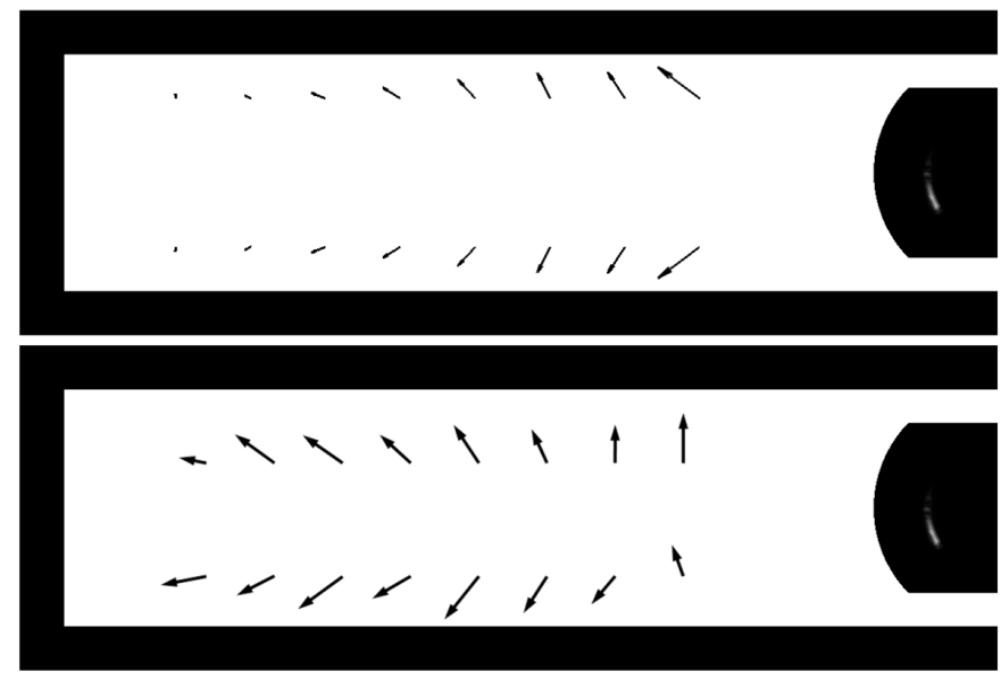

Figura 9. Padrão de fluxo no menisco para o caso B. Simulação (acima) e "Nail board" (abaixo). Fração volumétrica de argônio: $20 \%$. 

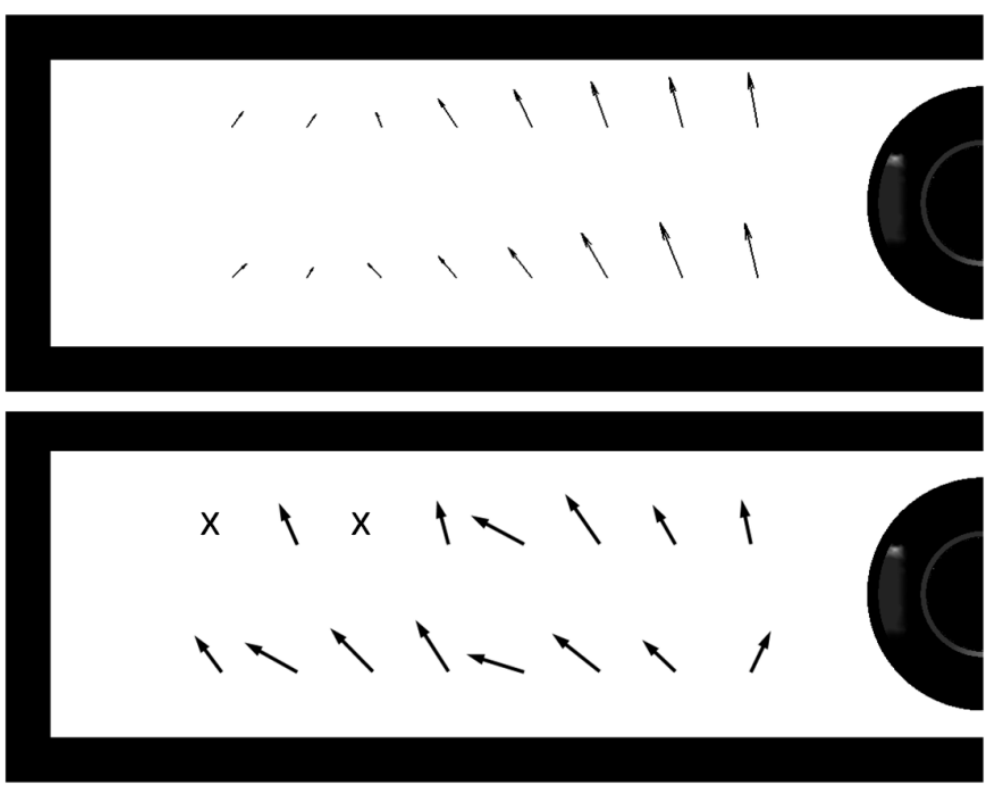

Figura 10. Padrão de fluxo no menisco para o caso C. Simulação (acima) e "Nail board" (abaixo). Fração volumétrica de argônio: $17 \%$.

As diferenças observadas, decorrentes de oscilações nos vetores obtidos pelo método experimental e que não são visualizadas nos resultados da simulação, podem ser explicadas pelo fato de que a simulação resolve o escoamento buscando valores médios ao longo do tempo, o que filtra as oscilações turbulentas. Por esse motivo, o resultado numérico tende a apresentar variações mais suaves do que os resultados experimentais.

Para o caso A, é possível observar a predominância de fluxo seguindo da face estreita em direção à válvula submersa, o que caracteriza um padrão "double roll" (veja Figura 4).

Já para os casos B e C, a alta vazão de gás provoca uma reversão do fluxo, que passa a predominar no sentido de fluir da válvula em direção à face estreita o que caracteriza um padrão "single roll". Para o caso C, é possível observar a existência de uma forte assimetria transversal do fluxo no menisco, comportamento típico de controle de fluxo por válvula gaveta pelo estrangulamento do jato de aço. A alta taxa de injeção de gás intensifica a assimetria.

Uma vez validado qualitativamente, o modelo numérico pode ser utilizado para a visualização do padrão de fluxo no molde em regiões além do menisco. A Figura 11 mostra o comportamento do fluxo para os 3 casos estudados: 

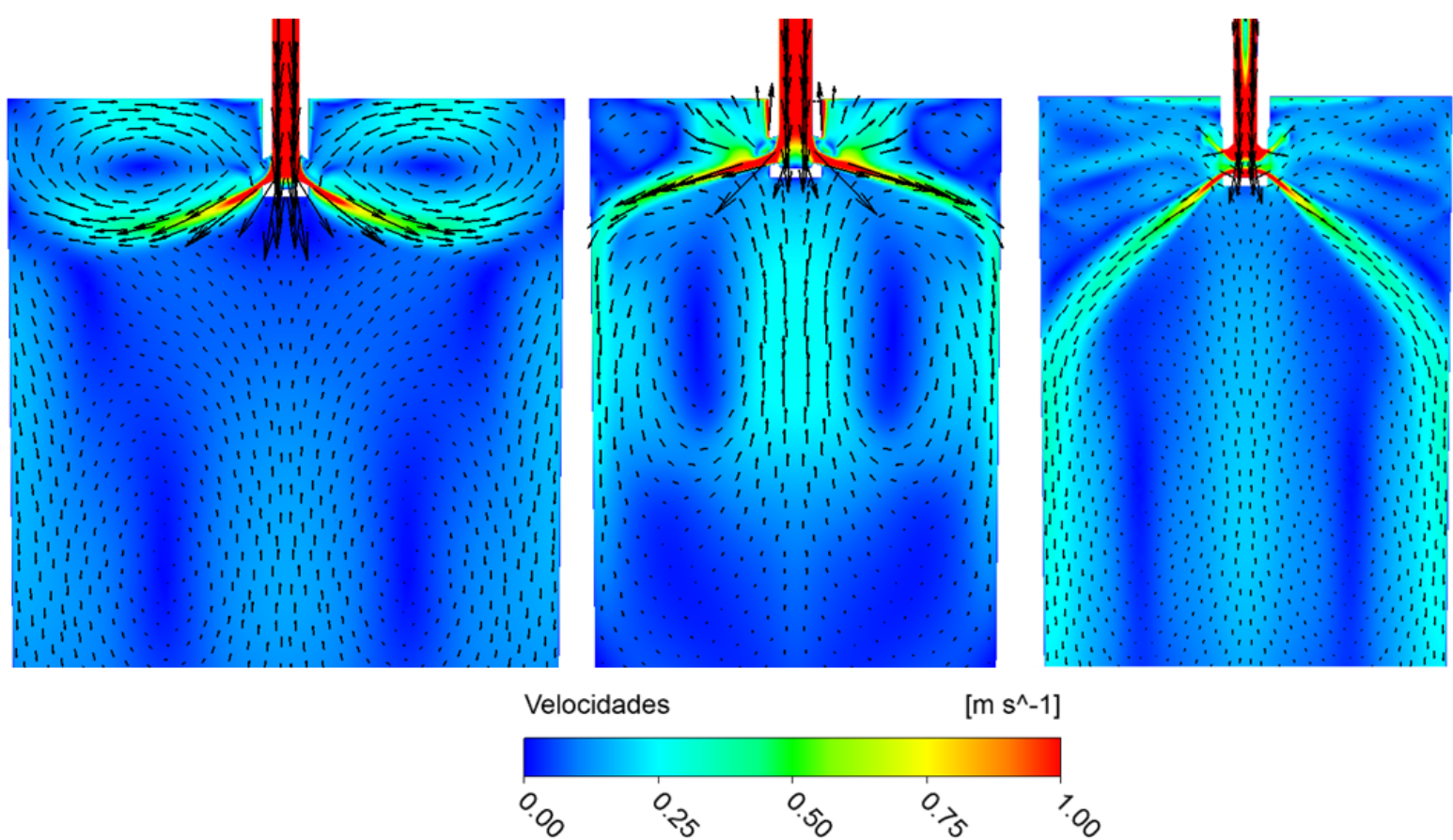

Figura 11. Padrão de fluxo no molde para os casos A, B e C (ordenados da esquerda para a direita).

Através dos resultados é possível confirmar o padrão de fluxo "double roll" para o caso A e "single roll" para os casos B e C.

A fim de verificar o impacto do argônio no padrão de fluxo "single roll" obtido para as configurações $B$ e $C$, esses dois casos foram simulados para uma condição em que não há injeção de gás. A Figura 12 mostra os resultados obtidos, que evidenciam a forte influência do argônio no padrão de fluxo do molde, uma vez que sem a injeção de gás, obteve-se um padrão "double roll" para ambos os casos.
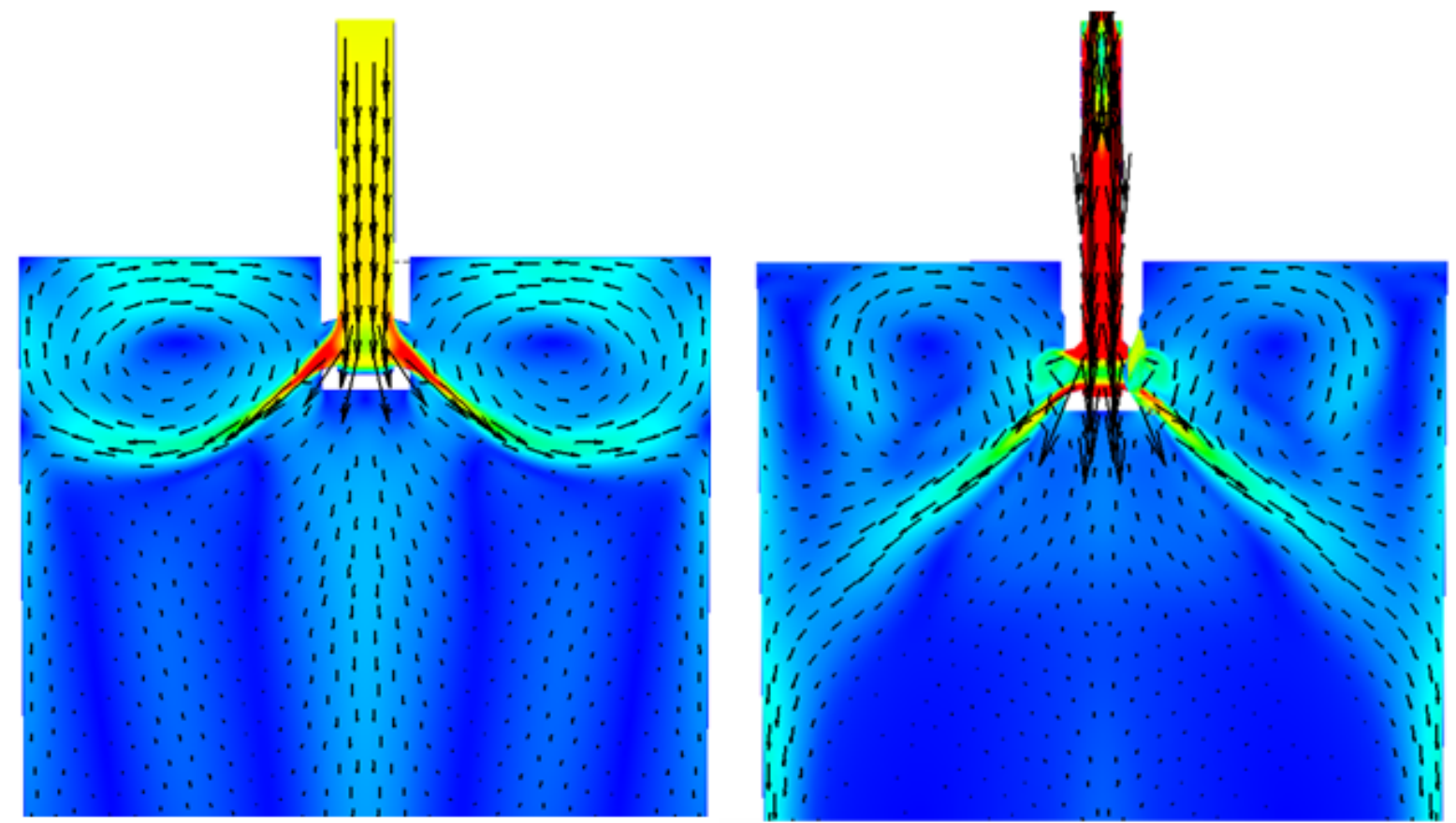

Figura 12. Padrão de fluxo no molde para os casos B e C, sob a condição de ausência de injeção de gás. 


\section{CONCLUSÃO}

O argônio possui papel importante na prevenção de "clogging" e remoção de partículas não metálicas, o que faz com que sua eliminação completa do lingotamento seja difícil do ponto de vista prático. Podemos tratá-lo como um "mal necessário". No entanto, os resultados apresentados neste trabalho mostram que deve haver critério em seu uso, uma vez que a prática de trabalhar-se com uma fração volumétrica de argônio elevada impacta negativamente no padrão de fluxo no molde.

De acordo com Dauby et al. [9], o padrão de fluxo "single roll" pode provocar trincas longitudinais pela pequena espessura de camada líquida de escória próximo à válvula submersa e defeitos por inclusões não metálicas e por aprisionamento de bolhas de argônio. Já o padrão "double roll" possui as características mais desejáveis do ponto de vista da qualidade do produto lingotado, já que a divisão do jato após o impacto na face estreita gera uma zona de recirculação superior que garante a manutenção da temperatura do menisco, bem como auxilia na captura pela escória do molde de quaisquer bolhas e partículas não metálicas na região do menisco.

Sugere-se, portanto, a avaliação do padrão de fluxo para cada condição de lingotamento através da metodologia "Nail Board", com foco nas condições que possuam maiores índices de defeito. Dessa forma, com baixo custo, é possível conhecer a influência de cada variável operacional no padrão de fluxo. As variáveis seriam: dimensões da placa, velocidade de lingotamento, vazão de argônio, imersão e projeto da válvula submersa. Considerando que as dimensões da placa são determinadas pela carteira de produção, essa avaliação permitirá a transição do padrão de fluxo "single roll" para "double roll" através da redução da vazão de argônio quando necessário. Estudos futuros podem ser realizados analisando-se a influência da imersão e projeto da válvula submersa.

O resultado dessa avaliação permite traçar os domínios "single roll" e "double roll" no diagrama largura/velocidade de lingotamento, fixadas as demais variáveis operacionais, conforme sugerido por Dauby et al. [9]. Um exemplo dessa análise gráfica está representado na Figura 13.

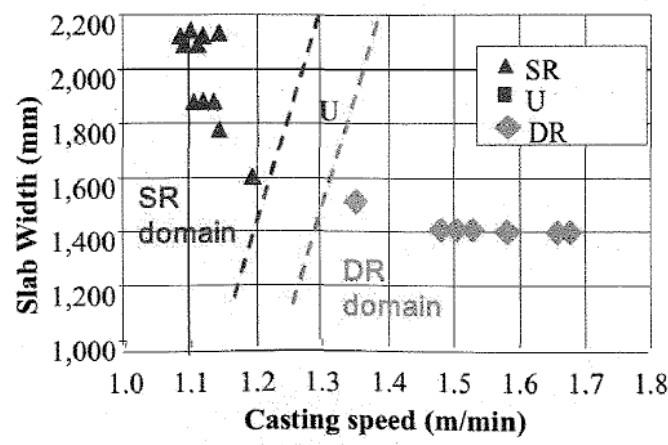

Figura 13. Domínios de padrão de fluxo no diagrama largura/velocidade de lingotamento (Dauby et al. [9]).

\section{Agradecimentos}

Ao "Continuous Casting Consortium" (CCC) e ao Professor e Pesquisador Brian Thomas pelos serviços prestados aos estudos do processo de lingotamento contínuo e seus impactos na qualidade do produto final. 


\section{REFERÊNCIAS}

1 Thomas BG. Fluid Flow in the Mold. The Making, Shaping and Treating of Steel, A.W. Cramb. The AISE Steel Foundation. 11 ${ }^{\text {a }}$ Edição; 2003; Casting Volume.

2 Thomas BG, Huang X., Sussman RC. Simulation of Argon Gas Flow Effects in a Continuous Slab Caster. Metallurgical and Materials Transactions B; 1994; Volume 25B.

3 Liu R, Sengupta J, Crosbie D, Chung, S, Trinh M, Thomas BG. Measurement of Molten Steel Surface Velocity with SVC and Nail Dipping During Continuous Casting Process, TMS: The Minerals, Metals and Materials Society; 2011; Annual Meeting.

4 Rice J, Faghri A. A New Computational Method for Free Surface Problems; Numerical Heat Transfer, Part B: Fundamentals.; 2006; Volume 49, Iss. 5.

5 Dauby PH, Emling WH, Sobolewski R. Lubrication in the Mold: A Multiple Variable System. Ironmaker and Steelmaker; 1986.

6 Thomas BG, Cukierski K. Flow Control with Local Electromagnetic Braking in Continuous Casting of Steel Slabs. Third Baosteel Biennial Conference; 2008; Volume 1.

7 Rietow T, Thomas BG. Using Nail Board Experiments to Quantify Surface Velocities in the CC Mold. AISTech Proceedings. 2008; Volume II.

8 Visser HH, Van der Knoop, W, Damen WFM, Van Essen TG, Van Oord J, Bal D, Higson SR, Brockhoff JPTM. Supplementary Tools to Measure and Understand the Flow in the Continuous Casting Mould. La Mettalurgia Italiana: Memorie - Colata Continua. 2009.

9 Dauby PH, Rotelec D. Real Flows in Continuous Casting Molds. AIST Transactions, Proceedings of the Roderick Guthrie Honorary Symposium on Process Metallurgy. 2011; Volume 6. 